\title{
Young breast cancer patients who develop distant metastasis after surgery have better survival outcomes compared with elderly counterparts
}

\author{
Jingjing Wang ${ }^{1}$, Jiayu Wang ${ }^{1}$, Qing Li ${ }^{1}$, Pin Zhang ${ }^{1}$, Peng Yuan ${ }^{1}$, Fei Ma ${ }^{1}$, Yang \\ Luo $^{1}$, Ruigang Cai ${ }^{1}$, Ying Fan ${ }^{1}$, Shanshan Chen ${ }^{1}$, Qiao $\mathrm{Li}^{1}$ and Binghe $\mathrm{Xu}^{1}$ \\ ${ }^{1}$ Department of Medical Oncology, Cancer Hospital, Chinese Academy of Medical Sciences and Peking Union Medical College, \\ Beijing, China \\ Correspondence to: Binghe Xu, email: xubinghecams@163.com \\ Keywords: breast cancer; young age; locoregional relapse; distant metastasis; prognosis \\ Received: November 09, $2016 \quad$ Accepted: January 11,2017 Published: Febraury 11, 2017
}

Copyright: Wang et al. This is an open-access article distributed under the terms of the Creative Commons Attribution License 3.0 (CC BY 3.0), which permits unrestricted use, distribution, and reproduction in any medium, provided the original author and source are credited.

\section{ABSTRACT}

To investigate the recurrence pattern and subsequent survival outcomes in young breast cancer population, 483 young patients $(\leq 35)$ and 739 elderly patients ( $\geq 65$ ), who received mastectomy or breast-conserving surgery from 2008 to 2012, were included in this study. The young population presented with a higher rate of pathologic tumor stage $(P<0.001)$, positive pathologic lymph node $(P<0.001)$, grade III tumors $(P<0.001)$, and lymphovascular invasion $(P<0.001)$. With a median follow-up of 56.5 months, young patients had a significantly lower 5-year disease-free survival $(73.7 \%$ vs $83.4 \%, P=$ $0.001)$, while no difference in 5-year overall survival was observed $(91.7 \%$ vs $91.7 \%, P=0.721)$. The 5-year cumulative incidences of locoregional relapse $(8.9 \%$ vs $4.3 \%, P=0.009)$ and distant metastasis $(18.8 \%$ vs $9.5 \%$, $P<\mathbf{0 . 0 0 1 )}$ were significantly higher in the young population. However, for patients with distant metastasis, the survival outcomes were significantly better in the young patients (5-year overall survival since diagnosis: $60.0 \%$ vs $47.3 \%, P=0.025$; 5 -year overall survival after recurrence: $31.0 \%$ vs $24.3 \%, P=0.001$ ). Young breast cancer patients present with more aggressive clinicopathological features and have poor prognosis compared with elderly. But young patients with distant metastasis might have better survival outcomes.

\section{INTRODUCTION}

Breast cancer is the most common invasive cancer and the leading cause of death from cancer among women worldwide. Patients younger than 35 years of age are relatively rare, accounting for $2 \%-4 \%$ of all cases diagnosed annually in the west [1-3] but much more popular in Asia [3-6]. According to the Annual Report of Cancer Statistics in Korean in 2011, 13.2\% of breast cancer was $<40$ years of age, and $4.7 \%$ was $<35$ years of age [6].

It is believed breast cancer at a young age is associated with more aggressive biological behavior and worse prognosis than in elderly [5, 7-17], characterized by higher incidence of recurrence and higher risk of death, even when treated with more aggressive therapies [10-14]. However, instead of reporting the overall prognosis from early stage to recurrence, few studies have investigated on survival outcomes after patients develop locoregional relapse (LRR) or distant metastasis (DM). It is speculated that young patients is much more tolerable to intensive treatment therefore might have better survival after LRR or DM, despite a shorter disease-free survival (DFS) following the surgery.

In this study, we aimed to evaluate the recurrence pattern and survival outcomes following recurrence in young breast cancer patients when compared with elderly patients. 
Table 1: Patients' baseline characteristics

\begin{tabular}{|c|c|c|c|c|c|}
\hline & All & Age $\leq 35$ & Age $\geq 65$ & $\chi^{2}$ & $\mathbf{P}$ \\
\hline & $N=1222$ & $N=483(39.5 \%)$ & $N=739(60.5 \%)$ & & \\
\hline Family history & & & & 11.322 & 0.001 \\
\hline Breast cancer or ovarian cancer & 72 & $42(8.7)$ & $30(4.1)$ & & \\
\hline No & 1150 & $441(91.3)$ & 709 (95.9) & & \\
\hline Type of surgery & & & & 17.776 & $<0.001$ \\
\hline Mastectomy & 893 & $321(66.5)$ & $572(77.4)$ & & \\
\hline Breast-conserving surgery & 329 & $162(33.5)$ & $167(22.6)$ & & \\
\hline Histology & & & & 4.266 & 0.118 \\
\hline In situ & 76 & $23(4.8)$ & $53(7.2)$ & & \\
\hline Invasive & 1080 & $438(90.7)$ & $642(86.9)$ & & \\
\hline Others & 66 & $22(4.6)$ & $44(6.0)$ & & \\
\hline Tumor grade & & & & 15.512 & $<0.001$ \\
\hline Grade I & 76 & $20(5.3)$ & $56(7.9)$ & & \\
\hline Grade II & 599 & $221(58.8)$ & $378(65.1)$ & & \\
\hline Grade III & 282 & $135(35.9)$ & $147(25.3)$ & & \\
\hline Pathologic tumor stage & & & & 34.599 & $<0.001$ \\
\hline T0 & 73 & $22(4.6)$ & $51(6.9)$ & & \\
\hline $\mathrm{T} 1$ & 626 & $225(46.6)$ & $401(54.3)$ & & \\
\hline $\mathrm{T} 2$ & 460 & $199(41.2)$ & $261(35.3)$ & & \\
\hline $\mathrm{T} 3$ & 31 & $26(5.4)$ & $5(0.7)$ & & \\
\hline $\mathrm{T} 4$ & 32 & $11(2.3)$ & $21(2.8)$ & & \\
\hline Pathologic tumor stage & & & & 11.991 & 0.001 \\
\hline T0-1 & 699 & $247(51.1)$ & $452(61.2)$ & & \\
\hline $\mathrm{T} 2-4$ & 523 & $236(48.9)$ & $287(38.8)$ & & \\
\hline Pathologic node status & & & & 19.717 & $<0.001$ \\
\hline No & 630 & $233(48.7)$ & $397(61.1)$ & & \\
\hline N1 & 280 & $129(27.0)$ & $151(23.2)$ & & \\
\hline $\mathrm{N} 2$ & 125 & $68(14.2)$ & $57(8.8)$ & & \\
\hline N3 & 93 & $48(10.0)$ & $45(6.9)$ & & \\
\hline Pathologic node status & & & & 16.989 & $<0.001$ \\
\hline N0 & 630 & $233(48.7)$ & $397(61.1)$ & & \\
\hline $\mathrm{N} 1-3$ & 498 & $245(51.3)$ & $253(38.9)$ & & \\
\hline Primary tumor size & & & & 24.969 & $<0.001$ \\
\hline$\leq 5 \mathrm{~cm}$ & 1175 & $448(92.8)$ & $727(98.4)$ & & \\
\hline$>5 \mathrm{~cm}$ & 47 & $35(7.2)$ & $12(1.6)$ & & \\
\hline ER & & & & 5.564 & 0.018 \\
\hline Positive & 917 & $345(71.4)$ & $572(77.4)$ & & \\
\hline Negative & 305 & $138(28.6)$ & $167(22.6)$ & & \\
\hline PgR & & & & 0.862 & 0.353 \\
\hline Positive & 875 & $353(73.1)$ & $522(70.6)$ & & \\
\hline Negative & 347 & $130(26.9)$ & $217(29.4)$ & & \\
\hline HER2 overexpression & & & & 20.770 & $<0.001$ \\
\hline Yes & 254 & $132(27.3)$ & $122(16.5)$ & & \\
\hline
\end{tabular}




\begin{tabular}{|l|c|c|c|c|c|}
\hline No & 968 & $351(72.7)$ & $617(83.5)$ & & \\
\hline Molecular subtype & & & & 32.774 & $<0.001$ \\
\hline ER/PgR+ and HER2- & 802 & $277(57.3)$ & $525(71.0)$ & & \\
\hline ER/PgR+ and HER2+ & 171 & $98(20.3)$ & $73(9.9)$ & & \\
\hline ER/PgR- and HER2+ & 85 & $35(7.2)$ & $50(6.8)$ & & \\
\hline ER/PgR- and HER2- & 164 & $73(15.1)$ & $91(12.3)$ & & \\
\hline Inflammatory breast cancer & & & & 0.133 & 0.715 \\
\hline No & 1194 & $471(97.5)$ & $723(97.8)$ & & \\
\hline Yes & 28 & $12(2.5)$ & $16(2.2)$ & & \\
\hline Lymphovascular invasion & & & & 23.199 & $<0.001$ \\
\hline No & 1108 & $414(85.7)$ & $694(93.9)$ & & \\
\hline Yes & 114 & $69(14.3)$ & $45(6.1)$ & & \\
\hline Adjuvant chemotherapy & & & & 447.438 & $<0.001$ \\
\hline No & 541 & $47(9.7)$ & $494(66.8)$ & & \\
\hline Anthracycline-containing chemotherapy & 446 & $333(68.9)$ & $113(15.3)$ & & \\
\hline Chemotherapy without anthracycline & 235 & $103(21.3)$ & $132(17.9)$ & & \\
\hline Adjuvant radiotherapy & & & & 238.343 & $<0.001$ \\
\hline No & 759 & $172(35.6)$ & $587(79.4)$ & & \\
\hline Yes & 463 & $311(64.4)$ & $152(20.6)$ & & \\
\hline Endocrine therapy & & & & 0.062 & 0.803 \\
\hline No & 321 & $125(25.9)$ & $196(26.5)$ & & \\
\hline Yes & 901 & $358(74.1)$ & $543(73.5)$ & & \\
\hline Trautuzumab & & & & 45.465 & $<0.001$ \\
\hline No & 1144 & $424(87.8)$ & $720(97.4)$ & & \\
\hline Yes & 78 & $59(12.2)$ & $19(2.6)$ & & \\
\hline
\end{tabular}

Abbreviations: ER: estrogen receptor; PgR: progesterone receptor; HER2: human epidermal growth factor receptor 2.

\section{RESULTS}

\section{Patient characteristics}

From January 2008 to December 2012, 1222 breast cancer patients were included in the study. $483(39.5 \%)$ of total population were younger than 35 years old. As shown in Table 1, more patients had a family history of breast cancer or ovarian cancer in the young population compared with elderly $(8.7 \%$ vs $4.1 \%, P=0.001)$. The young patients presented with a higher rate of pathologic tumor stage $(P<0.001)$, positive pathologic lymph node $(P<0.001)$, grade III tumors $(P<0.001)$, and lymphovascular invasion $(P<0.001)$. The incidence of triple negative breast cancer was also higher in young patients $(15.1 \%$ vs $12.3 \%, P<0.001)$. Furthermore, young patients were more likely to receive breast-conserving surgeries $(P<0.001)$, adjuvant chemotherapy $(P<0.001)$ and radiotherapy $(P<0.001)$.

\section{Survival analysis and prognostic factors}

After a median follow-up of 56.5 months, patients in the young population had a significantly lower 5-year DFS (Figure 1A, 73.7\% vs 83.4\%, $P=0.001$ ). Nonetheless, no significant difference in 5-year OS1 was observed (Figure $1 \mathrm{~B}, 91.7 \%$ vs $91.7 \%, P=0.721$ ).

In ER/PgR+ and HER2- disease, young patients were at increased risk of recurrence (5-year DFS rate: $75.2 \%$ vs $87.6 \%, P=0.001)$ compared with elderly; whereas no difference was observed in OS1 (5-year OS1 rate: $92.5 \%$ vs $92.9 \%, P=0.453$ ). On the other hand, there was no significant difference in DFS or OS1 between two populations in ER/PgR+ and HER2+, ER/PgR- and HER2+, or ER/PgR- and HER2- disease (data not shown).

Based on multivariate survival analysis, positive axillary lymph node and large primary tumor were negatively related to DFS $(P=0.032, \mathrm{HR}=0.578,95 \%$ $\mathrm{CI}=0.350-0.953)($ Table 2$)$ and OS1 $(P=0.031, \mathrm{HR}=$ $0.383,95 \% \mathrm{CI}=0.160-0.981$ ) (Table 3 ) in young patients. Similar results were observed in elderly patients (DFS: $P<$ 

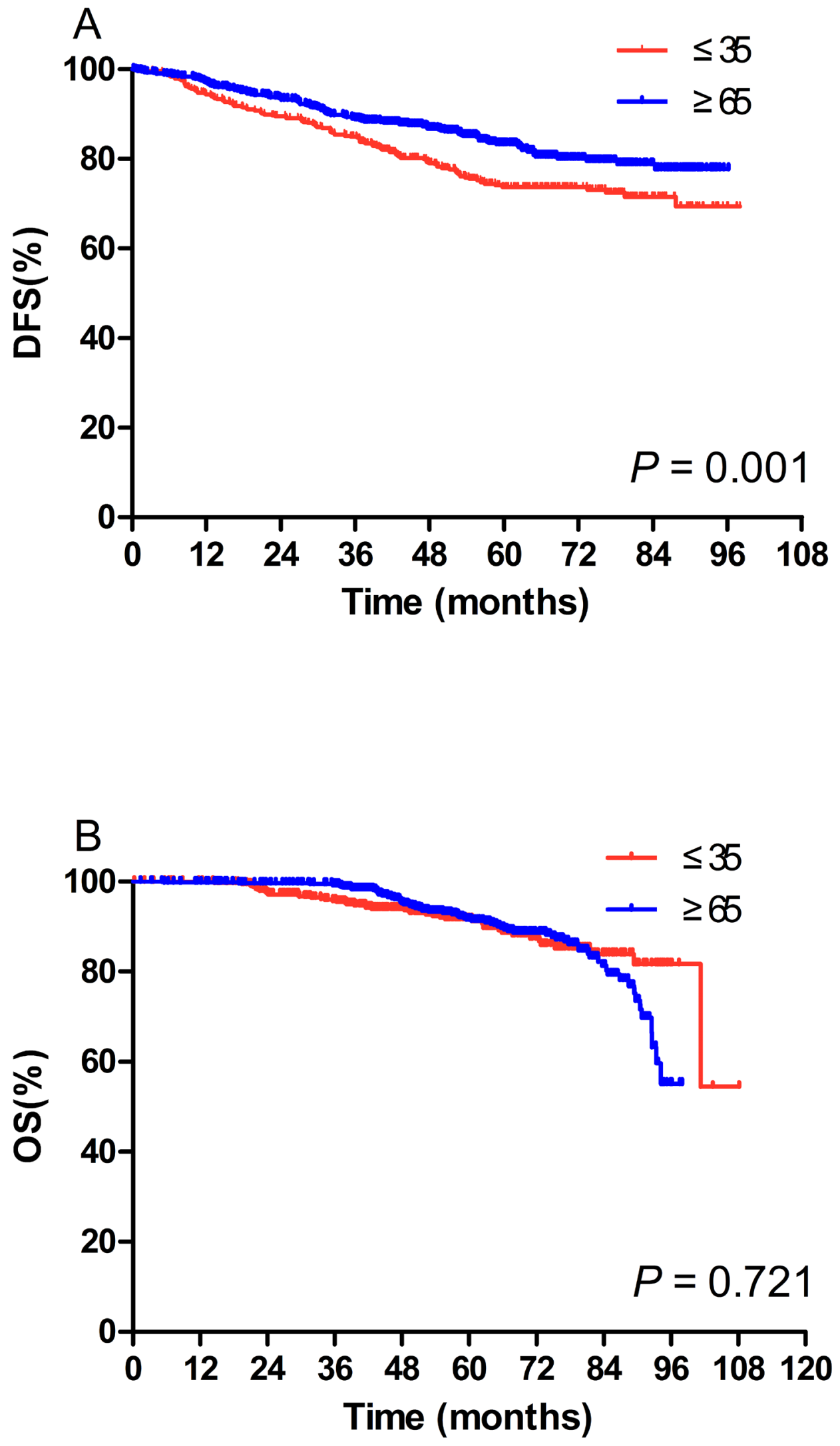

Figure 1: Kaplan-Meier curves of disease-free survival (DFS) (A) and overall survival (OS) (B) in the young population $(N=\mathbf{4 8 3})$ and the elderly population $(N=\mathbf{7 3 9})$. A. Patients in the young population had a significantly lower 5 -year DFS $(73.7 \%$ vs $83.4 \%, P=0.001)(73.7 \%$ vs $83.4 \%, P=0.001)$. B. No significant difference in 5-year OS1 was observed $(91.7 \%$ vs $91.7 \%, P=0.721)$. 
Table 2: Cox proportional hazards model for disease-free survival

\begin{tabular}{|c|c|c|c|c|}
\hline \multirow{2}{*}{ Variables } & Young group & & Old group & \\
\hline & HR(95\%CI) & $P$ & HR(95\%CI) & $P$ \\
\hline N1-3 & $0.578(0.350-0.953)$ & 0.032 & $0.271(0.167-0.440)$ & $<0.001$ \\
\hline Primary tumor size $>5 \mathrm{~cm}$ & $0.272(0.136-0.545)$ & $<0.001$ & $0.359(0.157-0.822)$ & 0.015 \\
\hline Lymphovascular invasion & $0.502(0.299-0.842)$ & 0.009 & $0.788(0.433-1.434)$ & 0.436 \\
\hline ER/PgR positive & $0.400(0.149-1.078)$ & 0.070 & $0.720(0.270-1.923)$ & 0.512 \\
\hline HER2 positive & $0.637(0.253-1.602)$ & 0.338 & $1.299(0.628-2.683)$ & 0.480 \\
\hline Adjuvant chemotherapy & $1.085(0.374-3.144)$ & 0.881 & $0.939(0.587-1.504)$ & 0.795 \\
\hline Adjuvant radiotherapy & $1.621(0.986-2.666)$ & 0.057 & $0.985(0.608-1.594)$ & 0.950 \\
\hline Endocrine therapy & $4.021(1.378-11.729)$ & 0.011 & $2.530(1.337-4.786)$ & 0.004 \\
\hline ER/PgR+ and HER2- & $1.731(0.578-5.182)$ & 0.326 & $0.634(0.239-1.681)$ & 0.360 \\
\hline
\end{tabular}

Abbreviations: HR: hazard ratio; CI: confidential interval; ER: estrogen receptor; PgR: progesterone receptor; HER2: human epidermal growth factor receptor 2 .

Table 3: Cox proportional hazards model for overall survival

\begin{tabular}{|l|c|c|c|c|}
\multirow{2}{*}{\multicolumn{1}{c|}{ Variables }} & Young group & & Old group & \\
\cline { 2 - 6 } & HR(95\%CI) & $\boldsymbol{P}$ & HR(95\%CI) & $\boldsymbol{P}$ \\
\hline N1-3 & $0.383(0.160-0.981)$ & 0.031 & $0.241(0.133-0.437)$ & $<0.001$ \\
\hline Primary tumor size $>5 \mathrm{~cm}$ & $0.242(0.101-0.581)$ & 0.001 & $0.241(0.097-0.579)$ & 0.002 \\
\hline Lymphovascular invasion & $0.405(0.183-0.897)$ & 0.026 & $0.678(0.327-1.405)$ & 0.295 \\
\hline ER/PgR positive & $2.586(1.254-5.331)$ & 0.010 & $0.931(0.270-3.216)$ & 0.910 \\
\hline HER2 positive & $0.668(0.192-2.326)$ & 0.527 & $1.183(0.490-2.856)$ & 0.709 \\
\hline Adjuvant chemotherapy & $2.571(0.473-13.974)$ & 0.274 & $1.790(1.009-3.179)$ & 0.047 \\
\hline Adjuvant radiotherapy & $1.336(0.576-3.098)$ & 0.500 & $0.926(0.495-1.731)$ & 0.809 \\
\hline Endocrine therapy & $1.819(0.243-13.591)$ & 0.560 & $1.530(0.640-3.657)$ & 0.339 \\
\hline ER/PgR+ and HER2- & $2.019(0.376-10.840)$ & 0.412 & $0.493(0.153-1.585)$ & 0.235 \\
\hline
\end{tabular}

Abbreviations: HR: hazard ratio; CI: confidential interval; ER: estrogen receptor; PgR: progesterone receptor; HER2: human epidermal growth factor receptor 2 .

$0.001, \mathrm{HR}=271,95 \% \mathrm{CI}=0.167-0.440, \mathrm{OS} 1: P<0.001$, $\mathrm{HR}=0.241,95 \% \mathrm{CI}=0.133-0.437)($ Table 2 and Table $3)$. For young population, ER or PgR positive patients presented with longer OS1 $(P=0.010, \mathrm{HR}=2.586,95 \%$ $\mathrm{CI}=1.254-5.331)$, but have a tendency to be with shorter DFS $(P=0.070, \mathrm{HR}=0.400,95 \% \mathrm{CI}=0.149-1.078)$. In the elder patients, longer OS1 was observed in patients who received adjuvant chemotherapy after surgery $(P=$ $0.047, \mathrm{HR}=1.790,95 \% \mathrm{CI}=1.009-3.179)$.

\section{Recurrence patterns}

At the last follow-up in young patients, we observed LRR in $28(5.8 \%)$ patients, DM in $72(14.9 \%)$, both LRR and DM in $8(1.7 \%)$, contralateral breast cancer in $6(1.2 \%)$, and other cancers in $1(0.2 \%)$ patients. In the elderly, the respective recurrence rates were $2.8 \%$ (28/739), 8.1\% (60/739), 0.1\% (1/739), 1.5\% (11/739), and $2.2 \%(16 / 739)$.
As shown in Figure 2, the 5-year cumulative incidences of LRR (8.9\% vs 4.3\%, $P=0.009)$ and DM (18.8\% vs $9.5 \%, P<0.001)$ were significantly higher in the young patients compared with elderly. In contrast, more elderly were diagnosed with other cancers in the follow-up period $(2.5 \%$ vs $0.2 \%, P=0.004)$. The 5-year cumulative incidences of contralateral breast cancer were similar between two populations $(1.8 \%$ vs $1.5 \%, P=$ $0.717)$.

\section{Prognosis after recurrence}

In order to further explore the survival difference between young and elderly populations, we carried out stratified analysis. As shown in Figure 3, in patients with DM, 5-year OS1 (5-year: 60.0\% vs 47.3\%, median: 70.9 vs 49.4 months, $P=0.025)$ and 5-year OS2 (31.0\% vs $24.3 \%, 38.8$ vs 12.1 months, $P=0.001)$ were significantly longer in the young patients compared with elderly; while 
no difference was observed in 5-year DFS between young cohort with DM and elderly group. In addition, in patients with LRR, contralateral breast cancer, or other cancers, no difference was observed in 5-year DFS, 5-year OS2 and 5 -year OS1 between age groups (data not shown).


\section{DISCUSSION}

It has been widely believed that breast cancer at a young age is associated with a more aggressive biological behavior although there was no consensus definition for


Figure 2: Cumulative incidence of locoregional relapse (LRR) (A), distant metastasis (DM) (B), contralateral breast cancer (C), and other cancers (D) according to age at diagnosis. A., B. The 5-year cumulative incidences of LRR (Figure 2A, $8.9 \%$ vs $4.3 \%, P=0.009$ ) and DM (Figure $2 \mathrm{~B}, 18.8 \%$ vs $9.5 \%, P<0.001$ ) were significantly higher in the young patients compared with elderly. C. The 5-year cumulative incidences of contralateral breast cancer were similar between two populations $(1.8 \% v s 1.5 \%, P=$ $0.717)$. D. More elderly were diagnosed with other cancers in the follow-up period $(2.5 \%$ vs $0.2 \%, P=0.004)$.


Figure 3: In the patients who developed distant metastasis after surgery, disease-free survival (DFS) (A), overall survival after recurrence $(\mathrm{OS} 2)(\mathrm{B})$, overall survival since diagnosis (OS1) (C) according to age. No difference was observed in 5-year DFS between young cohort with and elderly group. B., C. 5-year OS2 (Figure 3B, 31.0\% vs 24.3\%, 38.8 vs 12.1 months, $P=0.001$ ) and 5-year OS1 (Figure 3C, 5-year: 60.0\% vs 47.3\%, median: 70.9 vs 49.4 months, $P=0.025$ ) were significantly longer in the young patients compared with elderly. 
young breast cancer. Tumors in young women present with higher grade, higher $\mathrm{T}$ or $\mathrm{N}$ stage, lower differentiation, higher proliferating fraction and more vascular invasion [5, 7-17]. Azim and colleagues [18] reported that young patients had a significantly higher portion of basal-like tumors and HER2-enriched tumors. In our study, the clinicopathological characteristics of young patients were consistent with previous findings.

Following these facts, it is self-explanatory to associate young age with less favorable prognosis [5, 7-17]. Tang et al [15] demonstrated that after a follow-up of 54 months, patients $<40$ years of age had inferior 5-year DFS $(72 \%$ vs $83 \%, P<0.01)$ and 5 -year OS $(87 \%$ vs $93 \%$, $P<0.01)$ compared with those in 40-50. Consistently, lower 5-year DFS in young patients was also observed in our study $(62.2 \%$ vs $77.8 \%, P=0.037)$. In addition, a few recent studies suggested that the prognostic value of age differs by biologic subtypes. Sheridan et al [19] reported that age $<40$ was associated with inferior survival within the luminal subtypes. Tang et al [15] indicated that young patients with tumors classified as luminal B type were at increased risk of poor DFS and OS; in contrast, no significant DFS or OS difference between young and elderly was observed in HER2-positive or triple negative breast cancer. Our study, on the other hand, suggested young patients with luminal A subtype had worse survival outcomes. This slight inconsistency could be attributed to the variable definitions of molecular subtypes among different studies.

Importantly, few studies have evaluated the recurrence patterns after surgery and relevant clinical implications in young breast cancer patients. Cancello et al [12] reported that patients $<35$ years of age were at a higher risk to develop LRR $(P=0.0001)$ and DM $(P=0.0001)$ when compared with elderly (aged 35-50). Similar results were reported by De la Rochefordiere [20] and our group. A few studies have demonstrated that young age was an independent risk factor for increased LRR after breast-conserving surgeries in both intraductal and invasive diseases, despite given more aggressive adjuvant therapies [21-23]. Considering that higher portion of patients received breast-conserving surgery in young population in our study, the high risk of LRR in young patients could be partly attributed to the high rate of breast-conserving surgeries in our study. In addition, $\mathrm{DM}$ is the main recurrence pattern in young patients, much higher than LRR, justifying more intensive chemotherapy following surgery.

Despite the progress in recent years, more than $30 \%$ of patients diagnosed with early stage breast cancer will eventually progress to or relapse with advanced breast cancer [24-25]. And the overall survival for advanced breast cancer patients remains poor with a median survival ranging from 2 to 3 years [26-28]. In our study, we also compared the survival outcomes after recurrence in two populations. Better survival outcomes were observed in young patients with post-surgical DM but not with LRR. It is reasonable to speculate that young patients were able to receive more intensive treatments for better performance status and tolerability. Secondly, many patients in the elderly population died of causes other than breast cancer. Bastiaannet et al [29] investigated the relative survival (calculated as the ratio of the survival observed and the survival expected based on the corresponding general population) of elderly patients over young patients in 127,805 unselected population in Netherlands. It was reported that OS and relative survival decreased with age indicating the excess mortality in the elderly due to causes other than breast cancer. These data all suggested that in order to prolong survival, young breast cancer patients with DM should be given with more intensive treatments even the disease was incurable.

Admittedly, there were several limitations. Owing to the retrospective nature and nonrandomized design of the study, selection bias was inevitable. And the treatments were imbalanced between two populations. In HER2positive disease, more received trastuzumab in young patients (59/132 vs 19/122, 44.7\% vs 15.6\%).

In conclusion, young breast cancer patients present with more aggressive clinicopathological features and have poor prognosis compared with elderly. Although they were at a higher risk to develop LRR and DM after surgery, patients with DM might have better survival outcomes.

\section{MATERIALS AND METHODS}

\section{Patients}

From January 2008 to December 2012, patients with operable breast cancer who received surgery at the Cancer Hospital, Chinese Academy of Medical Sciences and Peking Union Medical College were systemically reviewed. The inclusion criteria for the study were: (1) $\leq 35$ years old or $\geq 65$ years old; (2) newly diagnosed breast cancer; (3) available pathology report of immunohistochemistry (IHC) for estrogen receptor (ER), progesterone receptor $(\mathrm{PgR})$, and human epidermal growth factor receptor 2 (HER2) status using tumor samples from core needle biopsy or surgery. The exclusion criteria were: (1) stage IV disease, bilateral breast cancer, male breast cancer, or patients complicated with other malignancies; (2) patients with incomplete medical record; (3) patients lost to follow-up immediately after treatment.

This was a retrospective observational study with information collected from hospital database. Patients' treatments or care was not interfered throughout the course. Therefore, ethical approval and patient consents were not required. 


\section{Treatment}

Clinical evaluations at the time of this study entry included medical history and physical examination, complete blood cell count, serum biochemistry (including hepatic function, renal function, and electrolytes), electrocardiogram, bilateral breast magnetic resonance imaging or ultrasound, chest X-ray, abdominal ultrasound or computed tomography scans.

All of the mastectomies and breast-conserving surgeries were R0 resection (margin-clear resection). Adjuvant chemotherapy and radiotherapy were used at the discretion of physicians in adherence to the treatment guidelines back then, followed by endocrine therapy in cases of ER or PgR positive. Trastuzumab was recommended to HER2-positive patients but not compulsory. The status of ER, PgR and HER2 were determined by IHC.ER or PgR positive was defined as at least $1 \%$ of tumor cells with positive nuclear staining. HER2 positive was defined as $3+$ by IHC or positive by fluorescent in situ hybridization. The study population was divided as: (1) ER/PgR+ and HER2-; (2) ER/PgR+ and HER2+; (3) ER/PgR- and HER2+; (4) ER/PgR- and HER2-.

\section{Statistical analysis}

All data were analyzed using SPSS medical statistical software (version 15.0). DFS was defined as the duration from the diagnosis of primary breast cancer to the date of LRR or DM or last follow-up; overall survival 1 (OS1) was defined as the period from the diagnosis of primary breast cancer to the date of patient death for any cause or last follow-up; overall survival 2 (OS2) was defined as the duration from the date of LRR or DM to the date of patient death for any cause or last followup. Both OS and DFS were analyzed using the KaplanMeier method. Comparisons of OS or DFS between groups were performed using log-rank test. A two-tailed $P<0.05$ was considered statistically significant. The Chisquared test was performed to compare the distribution of patient characteristics between young and old patients. Multivariate analysis was done using Cox's proportional hazard regression model, and hazard ratios (HR) were presented with $95 \%$ confidential intervals (CI).

\section{ACKNOWLEDGMENTS}

We thank all doctors and nurses of the department of medical oncology for their help in realization of this study.

\section{CONFLICTS OF INTEREST}

The authors declare no conflict of interest.

\section{REFERENCES}

1. Ries LAG. SEER Cancer Statistics Review, 1973-1999 Bethesda, MD: National Cancer institute.2002.

2. Siegel R, Ma J, Zou Z, Jemal A. Cancer statistics, 2014. CA Cancer J Clin. 2014; 64: 9-29.

3. Winchester DP. Breast cancer in young women. Surg Clin North Am. 1996; 76: 279-287.

4. Fan L, Strasser-Weippl K, Li JJ, St Louis J, Finkelstein DM, Yu KD, Chen WQ, Shao ZM, Goss PE. Breast cancer in China. Lancet Oncol. 2014; 15: e279-e289.

5. Han W, Kim SW, Park IA, Kang D, Kim SW, Youn YK, Oh SK, Choe KJ, Noh DY. Young age: an independent risk factor for disease-free survival in women with operable breast cancer. BMC Cancer. 2004; 4: 82-89.

6. Ministry of Health and Welfare. Annual Report of Cancer statistics in Korean in 2011. Goyang: Korean Central Cancer Registry. 2012.

7. Dubsky PC, Gnant MF, Taucher S, Roka S, Kandioler D, Pichler-Gebhard B, Agstner I, Seifert M, Sevelda P, Jakesz $\mathrm{R}$. Young age as an independent adverse prognostic factor in premenopausal patients with breast cancer. Clin Breast Cancer. 2002; 3: 65-72.

8. Maggard MA, O'Connell JB, Lane KE, Liu JH, Etzioni DA, Ko CY. Do young breast cancer patients have worse outcomes? J Surg Res. 2003; 113: 109-113.

9. Gajdos C, Tartter PI, Bleiweiss IJ, Bodian C, Brower ST. Stage 0 to stage III breast cancer in young women. J Am Coll Surg. 2000; 190: 523-529.

10. Han W, Kang SY. Relationship between age at diagnosis and outcome of premenopausal breast cancer: age less than 35 years is a reasonable cut-off for defining young age-onset breast cancer. Breast Cancer Res Treat. 2010; 119: 193-200.

11. Anders CK, Hsu DS, Broadwater G, Acharya CR, Foekens JA, Zhang Y, Wang Y, Marcom PK, Marks JR, Febbo PG, Nevins JR, Potti A, Blackwell KL. Young age at diagnosis correlates with worse prognosis and defines a subset of breast cancers with shared patterns of gene expression. J Clin Oncol. 2008; 26: 3324-3330.

12. Cancello G, Maisonneuve P, Rotmensz N, Viale G, Mastropasqua MG, Pruneri G, Veronesi P, Torrisi R, Montagna E, Luini A, Intra M, Gentilini O, Ghisini R, et al. Prognostic and adjuvant treatment effects in selected breast cancer subtypes of very young women $(<35$ years) with operable breast cancer. Ann Oncol. 2010; 21: 1974-1981.

13. Gnerlich JL, Deshpande AD, Jeffe DB, Sweet A, White $\mathrm{N}$, Margenthaler JA. Elevated breast cancer mortality in women younger than age 40 years compared with older women is attributed to poorer survival in early-stage disease. J Am Coll Surg. 2009; 208: 341-347.

14. Fredholm H, Eaker S, Frisell J, Holmberg L, Fredriksson I, Lindman H. Breast cancer in young women: poor survival despite intensive treatment. Plos One. 2009; 4: e7695.

15. Tang LC, Jin X, Yang HY, He M, Chang H, Shao ZM, 
Di GH. Luminal B sugtype: a key factor for the worse prognosis of young breast cancer patients in China. BMC Cancer. 2015; 15: 201-207.

16. Tang J, Wu CC, Xie ZM, Luo RZ, Yang MT. Comparison of clinical features and treatment outcome of breast cancers in young and elderly Chinese patients. Breast Care. 2011; 6: $435-440$.

17. Kim JK, Kwak BS, Lee JS, Hong SJ, Kim HJ, Son BH, Ahn SH. Do very young Korean breast cancer patients have worse outcomes? Ann Surg Oncol. 2007; 14: 3385-3391.

18. Azim HA Jr, Michiels S, Bedard PL, Singhal SK, Criscitiello C, Ignatiadis M, Haibe-Kains B, Piccart MJ, Sotiriou C, Loi S. Elucidating prognosis and biology of breast cancer arising in young women using gene expression profiling. Clin Cancer Res. 2012, 18: 1341-1351.

19. Sheridan W, Scott T, Caroline S, Yvonne Z, Vanessa B, David V, Karen G, Stephen C. Breast cancer in young women: have the prognostic implications of breast cancer subtypes changed over time? Breast Cancer Res Treat. 2014; 147: 617-629.

20. de la Rochefordiere A, Asselain B, Campana F, Scholl SM, Fenton J, Vilcoq JR, Durand JC, Pouillart P, Magdelenat $\mathrm{H}$, Fourquet A. Age as prognostic factor in premenopausal breast carcinoma. Lancet. 1993; 341: 1039-1043.

21. Early Breast Cancer Trialists' Collaborative Group (EBCTCG), Darby S, McGale P, Correa C, Taylor C, Arriagada R, Clarke M, Cutter D, Davies C, Ewertz M, Godwin J, Gray R, Pierce L, et al. Effect of radiotherapy after breast-conserving surgery on 10-year recurrence and 15-year breast cancer death: meta-analysis of individual patient data for 10,801 women in 17 randomised trials. Lancet. 2011; 378: 1707-1716.

22. Donker M, Litière $S$, Werutsky G, Julien JP, Fentiman IS, Agresti R, Rouanet P, de Lara CT, Bartelink H, Duez N, Rutgers EJ, Bijker N. Breast-conserving treatment with or without radiotherapy in ductal carcinoma in situ: 15-year recurrence rates and outcome after a recurrence, from the EORTC 10853 randomized phase III trial. J Clin Oncol. 2013; 31: 4054-4059.
23. van Laar C, van der Sangen MJ, Poortmans PM, Nieuwenhuijzen GA, Roukema JA, Roumen RM, TjanHeijnen VC, Voogd AC. Local recurrence following breastconserving treatment in women aged 40 years or younger: trends in risk and the impact on prognosis in a populationbased cohort of 1143 patients. Eur J Cancer. 2013; 49: 3093-3101.

24. Moreno-Aspitia A, Perez EA. Anthracycline- and/or taxane-resistant breast cancer: results of a literature review to determine the clinical challenges and current treatment trends. Clin Ther. 2009; 31: 1619-1640.

25. Oostendorp LJ, Stalmeier PF, Donders AR, van der Graaf WT, Ottevanger PB. Efficacy and safety of palliative chemotherapy for patients with advanced breast cancer pretreated with anthracyclines and taxanes: a systematic review. Lancet Oncol. 2011; 12: 1053-1061.

26. Hortobagyi GN, de la Garza Salazar J, Pritchard K, Amadori D, Haidinger R, Hudis CA, Khaled H, Liu MC, Martin M, Namer M, O’Shaughnessy JA, Shen ZZ, Albain KS, ABREAST Investigators. The global breast cancer burden: variations in epidemiology and survival. Clin Breast Cancer. 2005; 6: 391-401.

27. Roche H, Vahdat LT. Treatment of metastatic breast cancer: second line and beyond. Ann Oncol. 2011; 22: 1000-1010.

28. Jassem J, Carroll C, Ward SE, Simpson E, Hind D. The clinical efficacy of cytotoxic agents in locally advanced or metastatic breast cancer patients pretreated with an anthracycline and a taxane: a systematic review. Eur J Cancer. 2009; 45: 2749-2758.

29. Bastiaannet E, Liefers GJ, de Craen AJ, Kuppen PJ, van de Water W, Portielje JE, van der Geest LG, Janssen-Heijnen ML, Dekkers OM, van de Velde CJ, Westendorp RG. Breast cancer in elderly compared to younger patients in the Netherlands: stage at diagnosis, treatment and survival in 127,805 unselected patients. Breast Cancer Res Tr. 2010; 124: 801-807. 